\title{
Exploration behaviour and flight response toward a stimulus in three sea bass strains (Dicentrarchus labrax L.)
}

\author{
Sandie Millot ${ }^{\mathrm{a},{ }^{*}}$, Marie-Laure Bégout $^{\mathrm{a}}$ and Béatrice Chatain ${ }^{\mathrm{b}}$
}

\author{
a Ifremer, place du Séminaire, BP 5, 17137 L'Houmeau, France \\ ${ }^{\text {b }}$ Station expérimentale d'aquaculture, Ifremer, chemin de Maguelone, 34250 Palavas-les-Flots, France
}

*: Corresponding author : Sandie Millot, Tel.: +33 5465094 40; fax: +33 5465006 00, email address : Sandie.Millot@ifremer.fr

\begin{abstract}
:
Domestication and selection may affect fish behaviour, sometime as soon as at the first generation of domestication. However, knowledge about how both processes impact on fish spatial exploration and swimming activity still is to be improved. The objective of this experiment was (i) to evaluate spatial exploration behaviour and swimming activities of three sea bass strains having different domestication and selection levels and (ii) to analyse their responses to an acute stress. Sea bass exploration and swimming activities were studied before, during and $40 \mathrm{~min}$ after a stimulation (standardized fall of an object). The experimental tank was divided in to four zones, and the time spent, the distance travelled in each zone and the swimming complexity were quantified for each period from video recording. Results showed that fish from all strains presented the same flight response and that stimulus exposure induced a significant decrease in exploratory behaviour and swimming activity. The present study has also demonstrated that only one generation of captivity could be sufficient to obtain fish presenting the same behavioural characteristics than fish reared since at least two generations. Moreover, this study has highlighted that selection for growth seemed to select fish characterized by a bolder personality and potentially better adapted to rearing environment. It allowed us to suggest that selection for growth may have a higher effect on fish personality than domestication only.
\end{abstract}

Keywords: Domestication; Selection; Personality; Swimming activity; Danger avoidance; Risk assessment; Thigmotaxis 
In wild ecosystems, swimming behaviour of fish is very important for feeding, migrating or for escaping a predator (Wardle, 1993). That is also important in a captive environment where it influences access to food, adaptation to water flow rate and good positioning in the group. It is already established that chronic stress (e.g. change of water temperature, hypoxic conditions, photoperiod), or repeated acute stress (e.g. handling), modifies swimming velocity (Kristiansen et al., 2004; Olla and Studholme, 1971). Moreover, domestication and selection could have a rapid impact on fish behaviour, some time as soon as at the first generation of domestication (Bégout Anras and Lagardère, 2004; Huntingford, 2004; Vandeputte and Prunet, 2002). However, knowledge about how both processes impact on fish spatial exploration and swimming activity still is to be improved. Although, standardized stimulation has been mostly used to study the flight response in fish and particularly the "C-start” response in relation to different environmental constraints (group versus solitary response, Domenici and Batty, 1997; pollution, Faucher et al., 2006; water temperature, Johnson et al., 1996; hypoxia, Lefrançois and Domenici, 2006), few studies were focussed on the impact of domestication (Fernö and Järvi, 1998; Malavasi et al., 2004, 2008; Petersson and Järvi, 2006) and, to our knowledge, none targeted the impact of selection for growth on exploration behaviour. Main goal of the previous studies was to evaluate the domestication effect on juvenile fish survival and consequently their relevance for the enhancement of restocking programmes.

103 The present study had a different goal. It used the analysis of sea bass spatial exploration behaviour 104 and swimming activity level to determine whether three strains of sea bass (issued from wild, 105 domesticated and selected for growth parents) differed in their response to an acute stressor. Hereafter, we have evaluated the influence of domestication and selection process on risk taking behaviour and thus on fish personality (bold or shy; Fraser et al., 2001; Wilson et al., 1993, 1994). Accordingly, the purpose of this work was to measure the basic locomotory activity and the disorders induced by a

109 standardized stressor. Sea bass spatial exploration behaviour and swimming activity level were thus 110 monitored before, during and $40 \mathrm{~min}$ after a standardized stimulation. Fish were video-recorded and 111 their spatial exploration behaviour (spatial distribution and time spent), their swimming activity level 
112 (distance travelled) and their swimming path complexity (angular velocity) were analyzed in each tank

113 zone and during the three periods.

\section{Material and methods}

\subsection{Animals}

118 The experiment was conducted on 84 fish from three strains (28 fish per strain). The three tested

119 strains have been hatched and reared at the experimental research station of Ifremer in Palavas-les-

120 Flots (France). They are issued from a full factorial crossing (each dam is crossed with each sire) of 13

121 wild Mediterranean dams with 20 Atlantic wild sires (Wild strain), 20 Atlantic domesticated sires

122 (Domesticated strain) and 19 Atlantic selected sires (Selected strain) respectively. The Wild sires were

123 chosen among an Atlantic wild population kept in captivity for a least one year. The domesticated

124 sires have been obtained by choosing fish at random in a population reared for two years according to 125 sea bass rearing standards (Chatain, 1994) while the selected sires were the $5 \%$ longest fish at the 126 same age (20 months, $400 \mathrm{~g}$ ) in this same population. Thus all fish tested in this experiment never 127 experienced the natural environment, had the same life history except that their parents presented 128 different levels of domestication and selection. To summarize, Wild strain was characterized by fish 129 issued from wild parents with at least on year in captivity, Domesticated strain by parents with one 130 generation of captivity (i.e. domestication) and Selected strain by parents with one generation of 131 domestication and one generation of selection for growth.

132 At the beginning of the study, fish were around 20 month-old with an average initial body weight of $133234.8 \pm 9.5 \mathrm{~g}$ for Wild (coefficient of variation $(\mathrm{CV})=21 \%, \mathrm{n}=28$ fish), of $267.2 \pm 9.1 \mathrm{~g}$ for 134 Domesticated (CV = 17\%, $\mathrm{n}=28$ fish) and of $235.7 \pm 9.5 \mathrm{~g}$ for Selected (CV $=21 \%, \mathrm{n}=28$ fish). The 135 fish weight were not statistically different $\left(\mathrm{F}_{2,80}=1.46, \mathrm{p}>0.05\right)$.

\subsection{Experimental set up}

138 The experiment was carried out in a $400 \mathrm{l}$ tank similar to the ones used to maintain the experimental

139 fish. Water temperature was maintained at $20.2 \pm 1.5^{\circ} \mathrm{C}$, oxygenation above $90 \%$ saturation in the 
140 outlet and salinity $21.2 \pm 1$. Tank was sheltered by black curtains and highlighted by three spotlights

141 located to minimise shadow. The stimulus was a tube full of sand of $67 \mathrm{~g}, 96 \mathrm{~mm}$ length and $25 \mathrm{~mm}$

142 diameter, which fall was driven by an electromagnet (Fig.1A). An opaque pipe (1.6 m length, $35 \mathrm{~mm}$

143 diameter) was fixed $2 \mathrm{~cm}$ above the water surface to hide the stimulus during its fall and to allow the

144 recording of the fish reaction at the moment of impact (Fig. 1A). A Mini color CMOS camera

145 (Velleman) was located at $1.6 \mathrm{~m}$ of the water surface and video were recorded on a hard disk recorder

$146 \quad$ (Fig.1A).

147

148

\subsection{Behavioural test}

149 A single fish was quickly moved from its maintenance tank to the experimental tank two hours before the experiment started. According to Marino et al. (2001) a capture and handling procedure of short duration in two year old hatchery sea bass did not induce any significant variation in blood parameters, such as serum glucose or cortisol. Even if the procedure to place fish in the experimental tank involved

153 stress, the procedure was standardized for each fish and thus allowed to evaluate the swimming

154 responses for each individual in the same way.

155 Video recording begun 30 min before starting the test and fish homogeneous swimming in the entire 156 tank was required before stimulation. The stimulus was dropped by releasing the electromagnet when 157 the fish reached the stimulation zone (Fig.1B). Fish behaviour was recorded during one hour after the 158 stimulation (Fig.2). Fish which never swam in the tank and which thus could not be stimulated were 159 characterised as "shy" fish. Fish which presented a homogeneous swimming in the tank and which 160 could be stimulated were characterised as more "bold" and their exploration behaviour was further 161 analysed.

162 After the test, fish were removed from the experimental tank and placed in a separate tank to avoid 163 alarm pheromone release within the fish group which remained to be tested.

164

165 2.4. Video analyses 
The video recordings were analysed using the software EthoVision Color Pro version 3.1.16 (Noldus,

167 The Netherland), which allowed to separate the tank in 4 virtual zones of the same surface (Z1, Z2, Z3

168 and Z4; Fig.1B) and to track the fish swimming behaviour (Fig.2).

169 Each video recording were analysed in 3 sequences of 20 min:

- $\quad$ sequence $1(\mathrm{~S} 1)$ : before the stimulation

- $\quad$ sequence 2 (S2): just after the stimulation

- $\quad$ sequence 3 (S3): 40 min after the stimulation

\subsection{Statistics}

Different variables of interest were chosen to analyze the fish behaviour:

- The time taken from the start of recordings to the moment of the stimulation. This variable allowed to measure individual latency before stimulation.

- The proportion of time spent by a fish in each zone (residence; in \%). This variable allowed to identify the fish spatial distribution for each sequence.

- The distance travelled by each fish in the tank (in $\mathrm{cm}$ ). This variable quantified the fish swimming activity level in the tank for each sequence.

- $\quad$ The fish angular velocity weighted by the time spent by the fish in each zone (in degrees. $\mathrm{s}^{-1}$ ). This variable was calculated for each fish as followed:

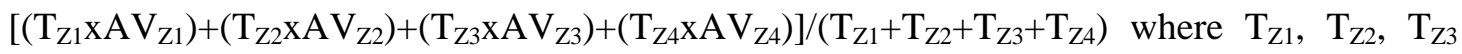
and $T_{\mathrm{Z} 4}$ were the time spent by the fish in each zone (s) and $A V_{\mathrm{Z} 1}, \mathrm{AV}_{\mathrm{Z} 2}, \mathrm{AV}_{\mathrm{Z3}}$ and $\mathrm{AV}_{\mathrm{Z} 4}$ were the individual angular velocity in each zone (degrees. $\mathrm{s}^{-1}$ ). This variable was an indicator of the speed of changing direction and quantified the swimming path complexity in relation to time

190 All data were analyzed for normality with a Shapiro-Wilk test and for homoscedacity of variance with

191 a Bartlett's test; they all complied the rules for parametric statistics. Then, for the individual latency

192 before stimulation a one way ANOVA was used to compare the difference between strains. For the

193 fish spatial distribution, since tank zones were not independent a 2 fixed factors ANOVA was used to 
compare the differences between strains and sequences for zones 1 and 4 . A null model of space use

195 was tested: the fish spatial distribution was compared to a theoretical homogeneous distribution in Z1 196 and Z4 (25\% in each zone) by a Kolmogorov-Smirnov test. Similarly, the fish swimming activity was 197 compared to a theoretical homogeneous activity in Z1 and Z4 (25\% in each zone) by a Kolmogorov198 Smirnov test. For the fish swimming activity level and swimming path complexity a 2 fixed factors

199 ANOVA was used to compare the differences between strains and sequences. Homogeneous groups 200 were determined with the a posteriori Newman and Keuls test (Dagnélie, 1975). For all tests, 201 significant threshold was $\mathrm{p}<0.05$ and analyses were performed using Statistica software.

202

\section{Results}

204

205

\subsection{Proportion of stimulated fish}

The experiment was carried out on 28 fish of each strain. For the Wild strain, 16 fish (57\%) placed in the experimental tank could be stimulated, for the Domesticated strain 14 fish (50\%) and for the Selected strain 18 fish (64\%). The remaining fish could not be stimulated because either they were motionless near a tank wall or they swam close to the walls opposite to and never reached the stimulation zone. These fish were thereafter characterized as "shy" fish and excluded from the statistical analysis.

\subsection{Individual latency before stimulation}

214 After the acclimatization time (2 hours), the latency before fish stimulation was $13.3 \pm 2.7 \mathrm{~min}( \pm \mathrm{SE}$ ) 215 for Wild strain, $9.9 \pm 2.8 \mathrm{~min}$ for Domesticated strain and $8.7 \pm 2.7 \mathrm{~min}$ for Selected strain. The three 216 strains responses were not different $\left(\mathrm{F}_{2,44}=0.82, \mathrm{p}>0.05\right)$.

\subsection{Spatial distribution}

219 On all video recorded, 16 on Wild fish, 11 on Domesticated fish and 16 on Selected fish could be 220 analysed $(\mathrm{N}=43)$. 
221 There were no spatial distribution difference between strains for Z $1\left(F_{2,120}=0.59, p>0.05\right)$ and for $Z 4$

$222\left(\mathrm{~F}_{2,120}=0.99, \mathrm{p}>0.05\right)$. However, the time spent by fish changed over time in $\mathrm{Z} 1\left(\mathrm{~F}_{4,120}=12.96, \mathrm{p}<0.001\right)$

223 in for $\mathrm{Z} 4\left(\mathrm{~F}_{2,120}=16.98, \mathrm{p}<0.001\right.$; Fig.3). Indeed, in $\mathrm{Z} 1$, fish spent more time during $\mathrm{S} 1(30 \pm 2 \%)$ than

224 during S2 and S3 (14 \pm 3\% for both) and in Z4, fish spent more time during S2 (62 \pm 4\%) and S3

225 (53 $\pm 5 \%)$ than S1 (29 $\pm 3 \%)$. During S1 the fish spatial distribution corresponded to theoretical

226 homogeneous spatial distribution (25\% per zone) for Z1 ( $D=0.500, p>0.05)$ and for Z4 (D = 0.500,

$227 \mathrm{p}>0.05$ ). During S2 and S3 the observed fish spatial distribution were different than the theoretical

228 homogeneous spatial distribution ( $\mathrm{D}=0.600$, $\mathrm{p}<0.05$ for $\mathrm{Z} 1$ and $\mathrm{D}=0.900$, $\mathrm{p}<0.001$ for $\mathrm{Z} 4$ ).

229

\subsection{Swimming activity}

231

For all strains, fish travelled more distance during S1 (9480 $\pm 1090,9554 \pm 1522$ and $11761 \pm 914 \mathrm{~cm}$ for

Wild, Domesticated and Selected fish respectively) than during S2 (2798 $\pm 538,2665 \pm 1267$ and $7190 \pm 1413 \mathrm{~cm}$ for Wild, Domesticated and Selected fish respectively). During S3, the distance travelled increased $(4892 \pm 1302,4741 \pm 2415$ and $7503 \pm 1041 \mathrm{~cm}$ for Wild, Domesticated and Selected fish respectively) but stayed at a lower level than during $\mathrm{S} 1\left(\mathrm{~F}_{2,120}=19.32, \mathrm{p}<0.0001\right.$; Fig.4). For each sequence, Selected fish travelled more distance than Wild and Domesticated fish, which were not different $\left(\mathrm{F}_{2,120}=6.87, \mathrm{p}<0.001\right.$; Fig.4). There was no significant interaction between sequence and strain factors $\left(\mathrm{F}_{4,120}=0.32, \mathrm{p}>0.05\right)$ which underlined an homogeneity in strains responses to the 239 standardized stressor. During S1, fish swimming activity was not different from the theoretical 240 homogeneous swimming activity in $\mathrm{Z} 1$ and $\mathrm{Z} 4(\mathrm{D}=0.500, \mathrm{p}=0.112)$. During S2 and S3, fish 241 swimming activity in Z1 were not different from the theoretical homogeneous swimming activity, 242 however they differed in $\mathrm{Z} 4(\mathrm{D}=0.800, \mathrm{p}<0.01$ for $\mathrm{S} 2$ and $\mathrm{D}=0.900, \mathrm{p}<0.001$ for $\mathrm{S} 3)$.

\subsection{Swimming path complexity}

245 For all strains, fish changed direction slower during S1 (24 $\pm 6,34 \pm 17$ and $11 \pm 3$ degrees. $\mathrm{s}^{-1}$ for Wild,

246 Domesticated and Selected fish respectively) than during S2 $\left(145 \pm 16,137 \pm 31\right.$ and $70 \pm 21$ degrees.s ${ }^{-1}$

247 for Wild, Domesticated and Selected fish respectively). 
248 During S3, the fish angular velocity decreased (72 $\pm 20,145 \pm 32$ and $32 \pm 210$ degrees.s ${ }^{-1}$ for Wild, 249 Domesticated and Selected fish respectively) but stayed at a higher level than during $\mathrm{S} 1\left(\mathrm{~F}_{2,120}=22.01\right.$, $250 \mathrm{p}<0.0001 ;$ Fig.5). For each sequence, Selected fish changed direction slower than Wild and 251 Domesticated fish, which were not different $\left(\mathrm{F}_{2,120}=11.15, \mathrm{p}<0.0001\right.$; Fig.5). There was no significant 252 interaction between sequence and strain factors $\left(\mathrm{F}_{4,120}=2.47, \mathrm{p}>0.05\right)$ which again underlined an 253 homogeneity in strains responses to the standardized stressor.

\section{Discussion}

\subsection{Basic locomotory activity}

The spatial exploration behaviour is generally considered as a good indicator of an animal adaptation to its environment. Indeed, such behaviour contributes to the construction of cognitive maps based on the coupling of space elements in which the animal moves (O'Keefe and Nadel, 1978). The capacities to explore an open field (potentially dangerous) could also depend on the animal personality (bold or shy). Indeed, for Fraser et al. (2001) and Wilson et al. (1993, 1994) boldness is considered as a personality trait and is generally defined as the propensity to take risks. According to our first results, it appeared that each strain presented different exploration behaviour and thus different environmental adaptation capacities, and the proportion of bold and shy fish was also different. Indeed, 64\% of Selected fish had been stimulated after only 9 min and they also showed a higher distance travelled in the tank and a lower swimming path complexity during the first experimental period compared to the other strains. Thus, Selected fish seemed characterized since the beginning of the experiment by a better environmental adaptation and a bolder personality than the other strains.

\subsection{Flight response and evolution of fish exploration behaviour}

273 Blanchard et al. $(1986,1989)$ showed in mice that two major systems of defense behaviour existed.

274 The first system could be observed when a threatening stimulus was physically present and

275 identifiable. This system which aims to reduce danger exposure toward threatening stimulus, involves 
flight or escape behaviour, which are typical of fear responses. The second system could be observed 277 during potential threatening situation when the stimulus was not clearly identifiable. This case 278 corresponded to a situation in which animals were previously frightened by the stimulus. They 279 presented then, three types of behaviour: avoidance of danger area, risk assessment (to evaluate and to locate) and thigmotaxis (tendency to remain close to the walls of an open field). These two major systems of defense were also observed in sea bass from the three strains tested during this experiment which mainly displayed both flight response and thigmotaxis. First, observations and video-tracking analysis showed that the stimulation induced for all fish a flight response in the opposite direction from the stimulus impact zone as illustrated by the significant increase of time spent in zone 4 . This zone could thus be defined as a "refuge" zone in which fish were characterized by a freezing behaviour, i.e. reduced swimming activity along the walls or total motionlessness. These results were in accordance with other studies realized on Dicentrarchus labrax (Malavasi et al., 2004, 2008), on Oncorhynchus kisutch (Ryer, 2004), on Calidris alpina (Barbosa, 1997), on Salmo trutta (Fernö and Järvi, 1998), on Salmo salar (Gotceitas and Godin, 1991), and on two species of stickleback Gasterosteus aculeatus and Pungitius pungitius (Godin and Valdron Clark, 1996). Such common flight response toward a threatening stimulus observed for all fish species, and for all strains in our case study, suggests that such behaviour has a strong innate determinant (Giles, 1984; Vilhunen and Hirvonen, 2003), could not be influenced by domestication and selection level and could thus be 294 considered as a fundamental component of anti-predator behaviour.

295 Second, swimming activity and spatial exploration seemed strongly impaired by the stimulation and 296 characterized by the second system of defense highlighted by Blanchard et al. (1986, 1989). The 297 significant higher residency in zone 4, the decrease of distance travelled, the increase of swimming complexity and the thigmotaxis behaviour in zone 4 were thus all typical indicators of fish avoidance of a dangerous area and of risk assessment. Forty minutes after the stimulation, fish recovered a higher level of spatial exploration and swimming activity i.e. fish globally showed a decreased residency in zone 4, an increase of distance travelled in the tank and a decrease in swimming complexity. These informations seemed to show that fish were less affected than just after the stimulation and began to 
return to the previous ones observed before stimulation, which indicated that fish remained fearful toward the stimulus.

306 Even if the general behavioural reaction of fish was the same in the three strains, Selected fish were still characterized by a higher swimming activity and a lower path complexity than other strains whatever the experimental sequences. Thus we could not conclude that Selected fish were differentially affected by stimulation than the other strains, but they were characterized since the beginning by a better environmental adaptation and a bolder personality which was kept during the entire test.

Malavasi et al. (2004, 2008) showed that hatchery-reared fish were characterized by a shorter stress response to threatening stimulation than fish of wild origin. In our experiment Wild and Domesticated fish presented the same spatial exploration behaviour and the same swimming activity. Therefore and since our Wild fish were not caught in the sea but issued from wild caught parents, our results could suggest that a twenty months period of rearing (first generation fish) could be sufficient to obtain fish presenting the same behavioural characteristics than second generation fish.

318 The behaviour and personality differences observed between Selected fish and the other fish strains in 319 our experiment could not be explained by behavioural deficits in anti-predator behaviour incurred through rearing in a psychosensory-deprived environment (Olla et al., 1994) or by the lack of some

321 key experiences in early life stage (Huntingford, 2004; Kelley and Maguran, 2003; Price, 1999),

322 because all of our fish were hatchery born and reared under the same conditions. Moreover, the 323 experiment was done on fish with similar weight for the three strains in order to limit any size 324 influence on behaviour since some studies have demonstrated that fish selected for their high growth 325 showed an increased willingness to accept risk (Biro et al., 2004; Fernö and Järvi, 1998; Huntingford 326 and Adams, 2005; Johnsson and Abrahms, 1991; Johnsson et al., 1996). Thus, the difference observed in our study could only be explained by the selection for growth process. We could then suggest that 328 parent selected for growth (and thus perhaps characterised by a better adaptation to rearing 329 environment) transmit this ability to their descendents. 
In conclusion, the present study has demonstrated that wild fish (i.e. Wild strain which was issued

332 from wild parents with at least on year in captivity) behave similarly to the domestic fish (i.e.

333 Domesticated strain). Further, selection for growth seemed to select fish characterized by a bolder 334 personality and potentially better adapted to rearing environment. Thus, selection for growth seemed to have a higher effect on fish personality and behaviour than domestication only. Nevertheless, to test

336 the perpetuation of domestication and/or selection effects on sea bass behaviour, personality and adaptability, it would be necessary to perform measurement on fish issued from following generations of domestication or selection.

\section{Acknowledgements}

We wish to thank N. Lachaussée, D. Leguay, P. Pineau and M. Prineau for their technical help, to C. Lefrançois for her scientific advices. Special thanks to B. Damsgård and T. Evenssen at Nofima

343 Marine for giving access to Ethovision software. We also wish to thank the two anonymous referees

344 for the improvement of the manuscript. This work was performed within the Integrated Research Project SEAFOODplus, contract no. FOOD-CT-2004-506359. The financing of this work by the European Union and by the county council of Charente Maritime is gratefully acknowledged. This study was conducted under the approval of the Animal Care Committee of France under the official licence of M.L. Bégout (17-010).

\section{References}

Barbosa, A., 1997. Foraging strategy and predator avoidance behaviour: an intraspecific approach. Acta Oecologica 18, 615-620.

Biro, P.A., Abrahams, M.V., Post, J.R., Parkinson, E.A, 2004. Predators select against high growth rates and risk-taking behaviour in domestic trout populations. Proc. Roy. Soc. B 271, 22332237.

Blanchard, R.J., Blanchard, D.C., Hori, K., 1989. Ethoexperimental approach to the study of defense, in: Blanchard, R.J., Brain, P.F., Blanchard, D.C., Parmigiani, S. (Eds.), Ethoexperimental Approaches to the Study of Behavior. Kluwer Academic Publishers, Dordrecht, pp. 114-136. 
Blanchard, R.J., Flannelly, K.J., Blanchard, D.C., 1986. Defensive behavior of laboratory and wild Rattus norvegicus. J. Comp. Psychol. 100, 101-107.

361

362

363

364

365

366

367

368

369

370

371

372

373

374

375

376

377

378

379

380

381

382

383

384

385

Bégout Anras, M.-L., Lagardère, J.-P., 2004. Domestication et comportement chez les poissons téléostéens. INRA Prod. Anim. 17, 211-215.

Chatain, B., 1994. Estimation et amélioration des performances zootechniques de l'élevage larvaire de Dicentrarchus labrax et de Sparus auratus. Thèse de Doctorat d'Etat, Univ. d'Aix-Marseille II 199 pp.

Dagnélie, P., 1975. Théorie et méthodes statistiques. Applications agronomiques vol. 2. Presses Agronomiques de Gembloux, Gembloux.

Domenici, P., Batty, R.S., 1997. Escape behaviour of solitary herring (Clupea harengus) and comparisons with schooling individuals. Mar. Biol. 128, 29-38.

Faucher, K., Fichet, D., Miramand, P., Lagardère, J.P., 2006. Impact of acute cadmium exposure on the trunk lateral line neuromasts and consequances on the "C-start" response behaviour of the sea bass (Dicentrarchus labrax L.; Teleostei, Moronidae). Aquatic Tox. 76, 278-294.

Fernö, A., Järvi, T., 1998. Domestication genetically alters the anti-predator behaviour of Anadromous brown trout (Salmo trutta) - a dummy predator experiment. Nordic J. Freshw. Res. 74, 95-100.

Fraser, D.F., Gilliam, J.F., Daley, M.J., Le, A.N., Skalsk, G.T., 2001. Explaining leptokurtic movement distributions: intrapopulation variation in boldness and exploration. Am. Nat. 158, 124-135.

Giles, N. 1984. Development of the overhead fright response in wild and predator - naïve three spined sticklebacks Gasterosteus aculeatus L. Anim. Behav. 32, 276-279.

Godin, J.G., Dugatkin, L.A., 1996. Female mating preference for bold males in the guppy, Poecilia reticulate. Proc. Natl. Acad. Sci. 93, 10262-10267.

Godin, J.G.J., Valdron Clark, K.A., 1996. Risk-taking in stickleback fishes faced with different predatory threats. Ecoscience 4, 246-251.

Gotceitas, V., Godin, J.G.J., 1991. Foraging under risk of predation in juvenile Atlantic salmon (Salmo salar L.): effects of social status and hunger. Behav. Ecol. Sociobiol. 29, 255-261. 
Huntingford, F.A., 2004. Implications of domestication and rearing conditions for the behaviour of cultivated fishes. J. Fish Biol. 65, 122-142.

Huntingford, F.A., Adams, C., 2005. Behavioural syndromes in farmed fish: implications for production and welfare. Behaviour 142, 1207-1221.

Johnsson, J.I., Abrahams, M.V., 1991. Interbreeding with domestic strain increases foraging under threat in juvenile steelhead trout (Oncorhynchus mykiss): an experimental study. Can. J. Fish. Aquat. Sci. 48, 237-247.

Johnson, T.P., Bennett, A.F., McLister, J.D., 1996. Thermal dependence and acclimation of fast start 394 locomotion and its physiological basis in rainbow trout (Oncorhynchus mykiss). Physiol. Zool. 69, 276-292.

Kelley, J.L., Magurran, A.E., 2003. Learned predator and antipredator responses in fishes. Fish Fish. 4, 216-226.

Kristiansen, T.S., Fernö, A., Hjolm, J.C., Privitera, L., Bakke, S., and Fosseidengen, J.E., 2004. Swimming behaviour as an indicator of low growth rate and impaired welfare in Atlantic

Lefrançois, C., Domenici, P., 2006. Locomotor kinematics and behaviour in the escape response of European sea bass, Dicentrarchus labrax L., exposed to hypoxia. Mar. Biol. 149 (4), 969-977.

Malavasi, S., Georgalas, V., Lugli, M., Torricelli, P., Mainardi, D., 2004. Differences in the pattern of antipredator behaviour between hatchery-reared and wild European sea bass juveniles. J. Fish Biol. 65, 143-155.

Malavasi, S., Georgalas, V., Mainardi, D., Torricelli, P., 2008. Antipredator responses to overhead fright stimuli in hatchery-reared and wild European sea bass (Dicentrarchus labrax L.) juveniles. Aquac. Res. 39, 276-282.

Marino, G., Di Marco, P., Mandich, A., Finoia, M.G., Cataudella, S., 2001. Changes in serum cortisol, metabolites, osmotic pressure and electrolytes in response to different blood sampling procedures in cultures sea bass (Dicentrarchus labrax L.). J. Appl. Ichthyol 17, 115-120.

O’Keefe, J., Nadel, L., 1978. The hippocampus as a cognitive map. Oxford, Clarendon. 
414 Olla, B.L., Studholme, A.L. 1971. The effect of temperature on the activity of bluefish, Pomatomus saltatrix L. Biol. Bull. 141, 337-349.

Olla, B.L., David, M.W., Ryer, C.H., 1994. Behavioural deficits in hatchery-reared fish: potential effects on survival following release. Aquac. \& Fish. Mngm. 25, 19-34.

Petersson, E., Järvi, T., 2006. Anti-predator response in wild and sea-ranched brown trout and their crosses. Aquaculture 253, 218-228.

Price, E.O., 1999. Behavioural development in animals undergoing domestication. Appl. Anim. Behav. Sci. 65, 245-271.

Ryer, C., 2004. Comparison of genetically based antipredator behaviour in hatchery and wild coho fry from a coastal Oregon river: interpreting a negative result. J. Fish Biol. 64, 1413-1418.

Vandeputte M., Prunet P., 2002. Génétique et adaptation chez les poissons : domestication, résistance au stress et adaptation aux conditions de milieu. INRA Prod. Anim. 15, 365-371.

Vilhunen, S., Hirvonen, H., 2003. Innate antipredator responses of Arctic charr (Salvelinus alpinus) depend on predator species and their diet. Behav. Ecol. Sociobiol. 55, 1-10.

Wardle, C.S., 1993. Fish behaviour and fishing gear, in: Pitcher, T.J. (Ed), Behaviour of teleost fishes ( $2^{\text {nd }}$ Edition). Chapman and Hall. pp. 609-644.

Wilson, D.S., Clark, A.B., Biederman, L., 1993. Shy bold continuum in pumpkinseed sunfish (Lepomis gibbosus): an ecological study of a psychological trait. J. Comp. Psychol. 107, 250260. other animals. Trends Ecol. Evol. 9, 442-446. 


\section{Figure captions}

Figure 1. (A) Representative scheme of the experimental set up to a scale of $1 / 20$ and (B) the zones delimitation on the tank bottom to a scale of 1/10.

Figure 2. Representative pictures of one fish swimming behavior for each of the 3 sequences in correspondence with the experimental time scale.

Figure 3. Proportion of time spent (mean \pm SE, in \%) by a fish in each tank zone for each sequence and for each strain.

Figure 4. Distance travelled (mean $\pm \mathrm{SE}$ in $\mathrm{cm}$ ) by a fish in the tank for each sequence and for each strain. Letters indicate significant differences between strains (2 fixed factors ANOVA and Newman \& Keuls test, $\mathrm{p}<0,05)$.

Figure 5. Fish angular velocity weighted by the time spent by the fish in each tank zone (mean $\pm \mathrm{SE}$ in degrees. $s^{-1}$ ) for each sequence and for each strain. Letters indicate significant differences between strains (2 fixed factors ANOVA and Newman \& Keuls test, $\mathrm{p}<0,05$ ). 


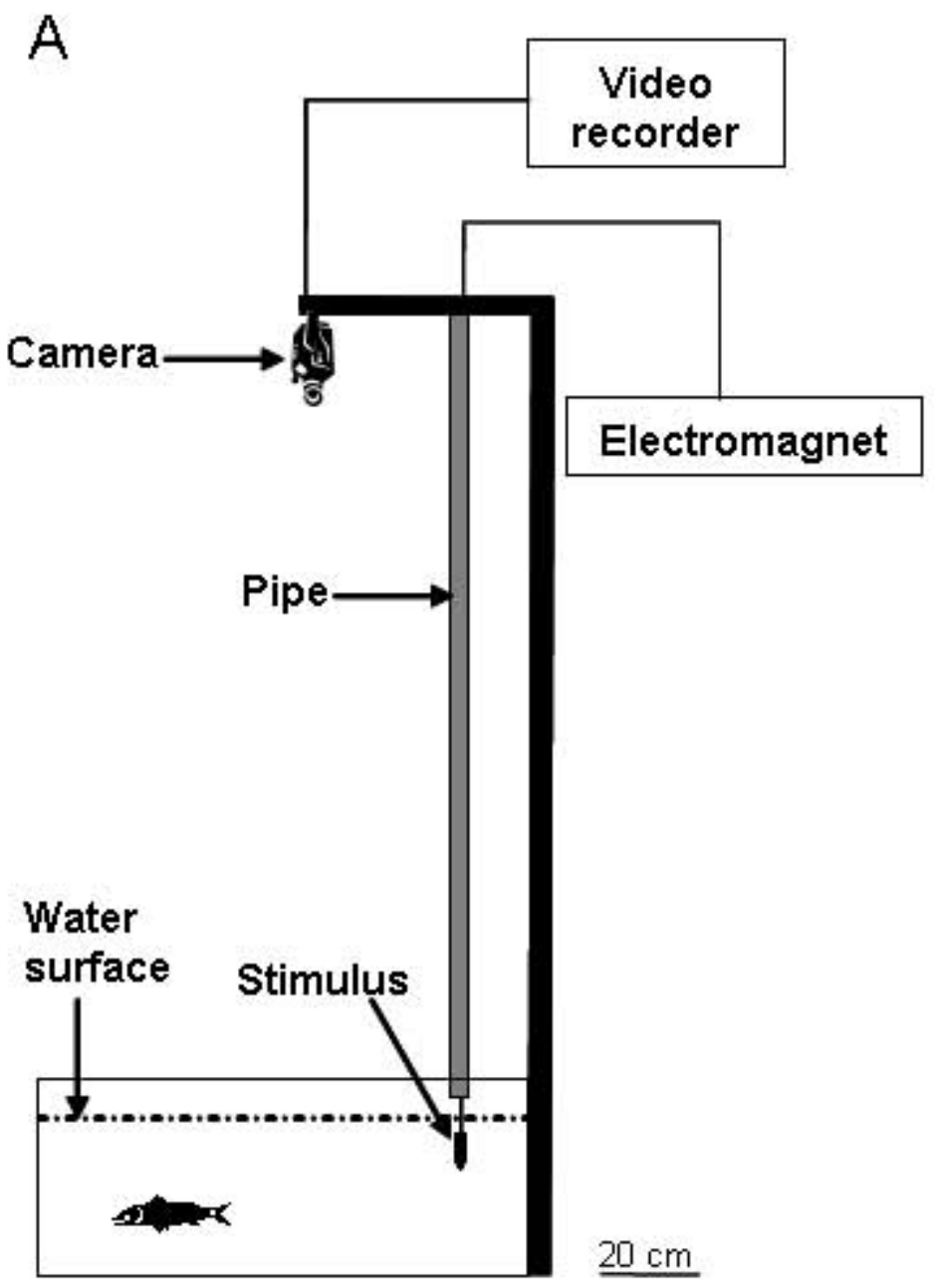

B

Zone 4

Zone 3

Zone 2

Zone 1

Stimulation

zone

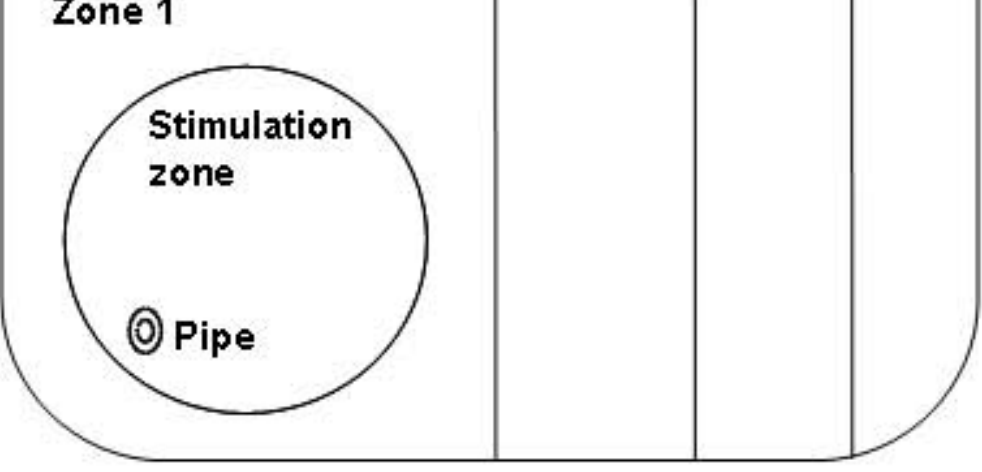

$10 \mathrm{~cm}$ 
SEQUENCE 1
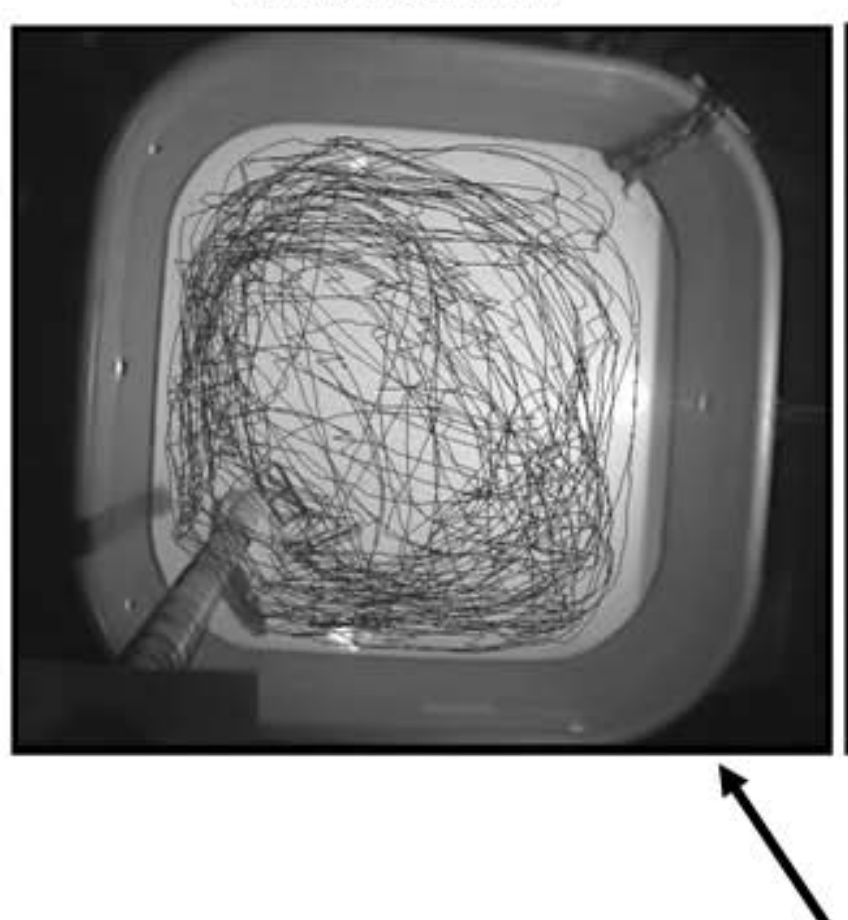

SEQUENCE 2

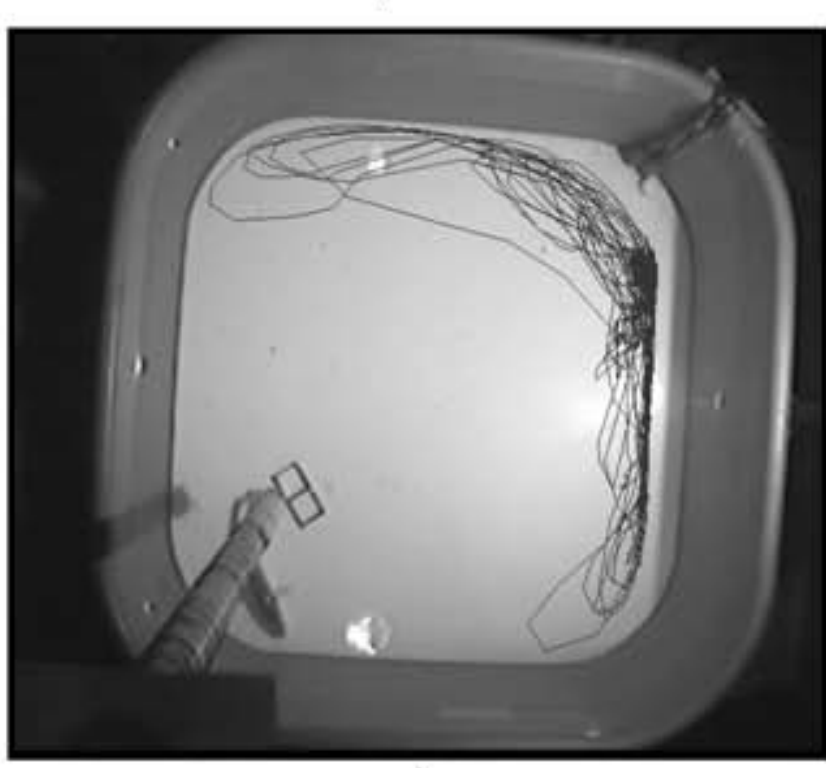

|

$$
20^{3}
$$

$2 \mathrm{~h}$
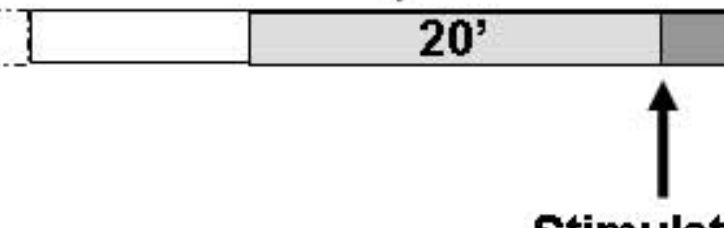

$20^{3}$

SEQUENCE 3

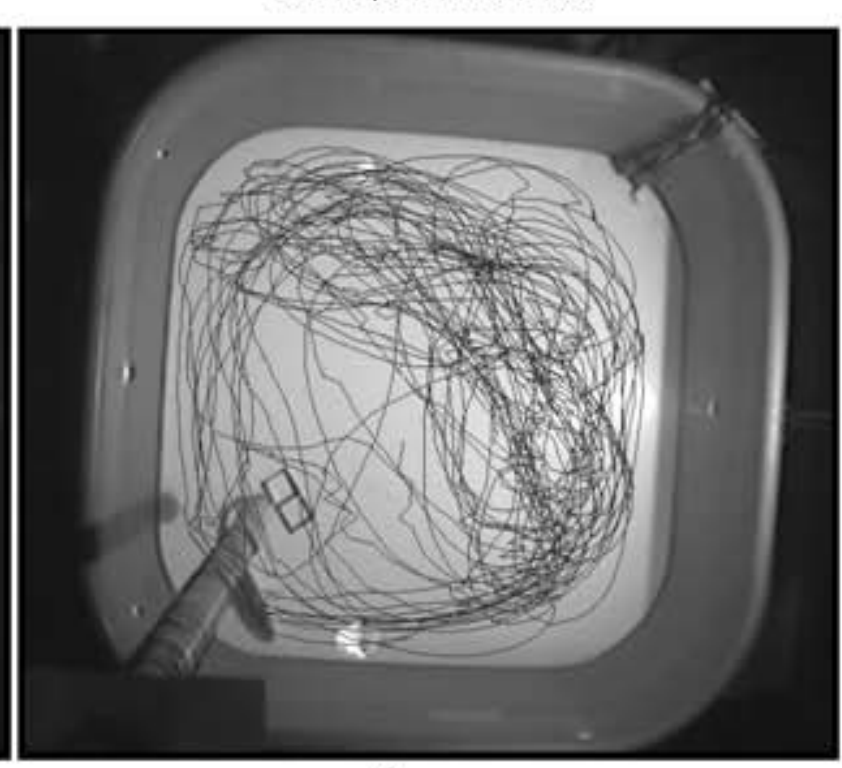

Stimulation 
Zone 1

口Zone 2

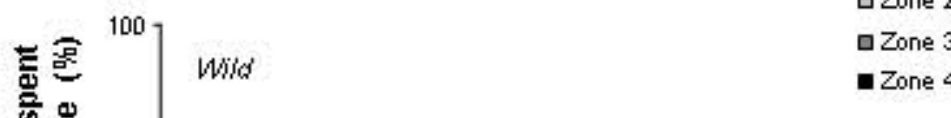

क⿺

를

.

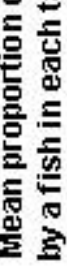
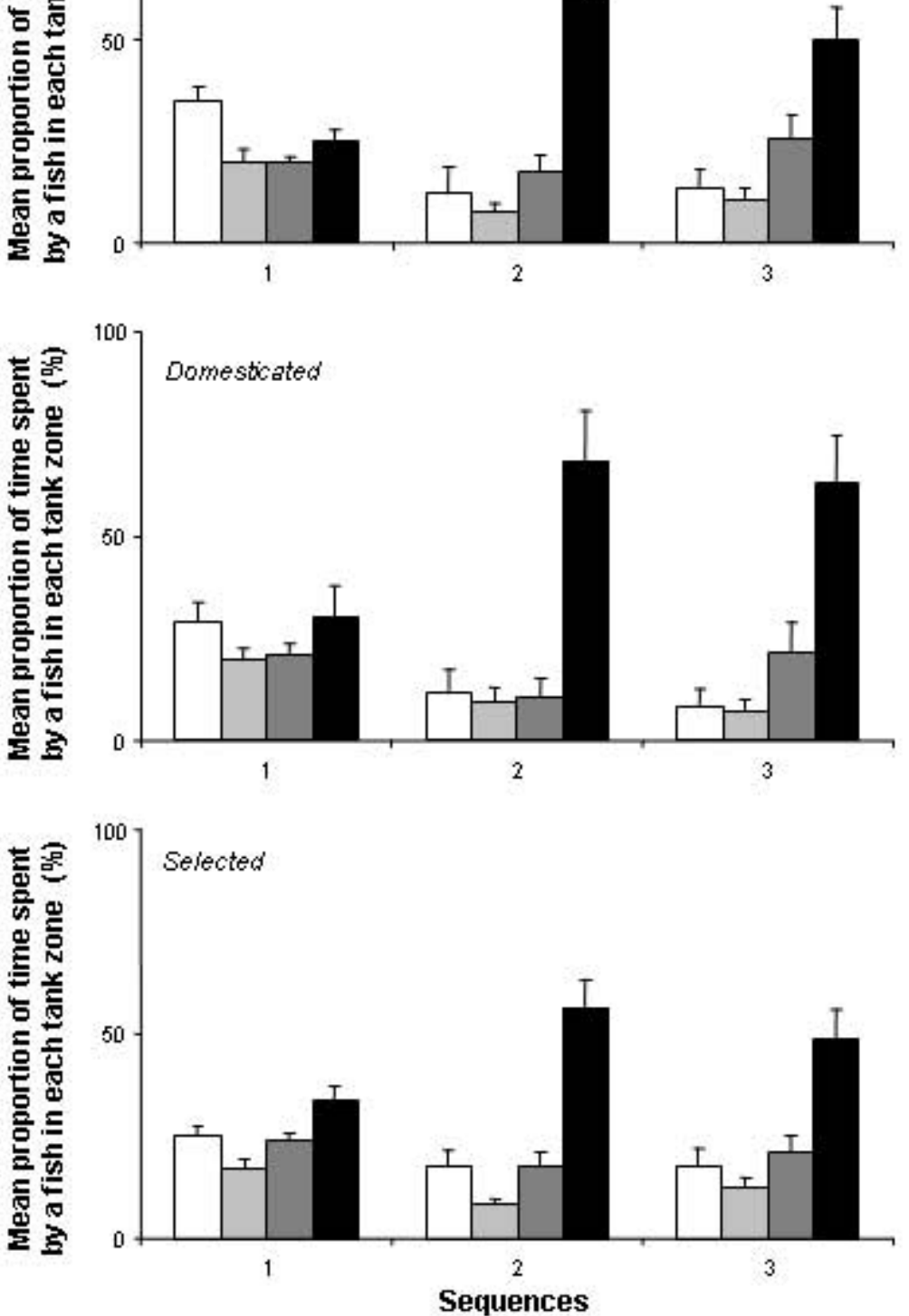


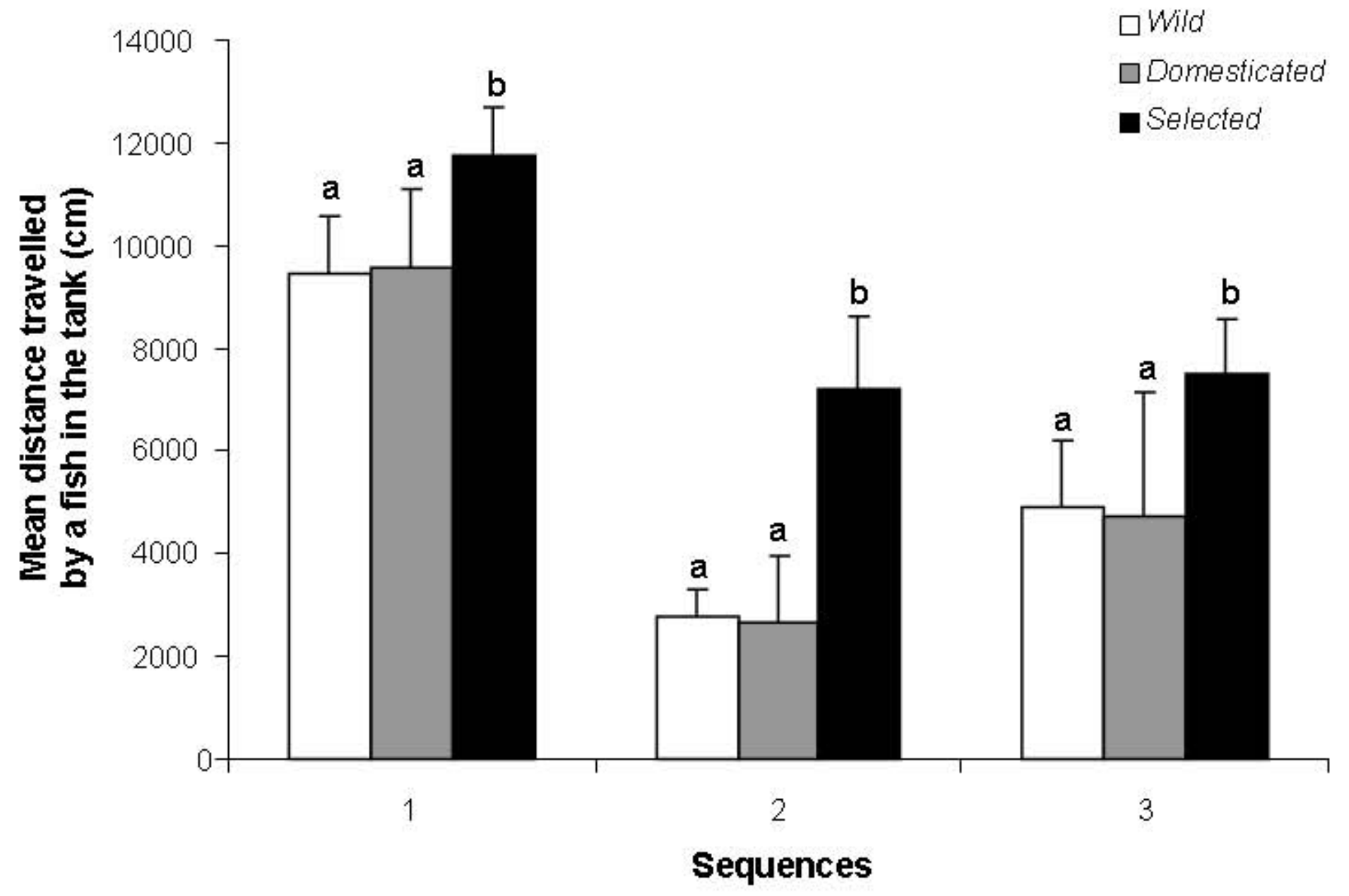




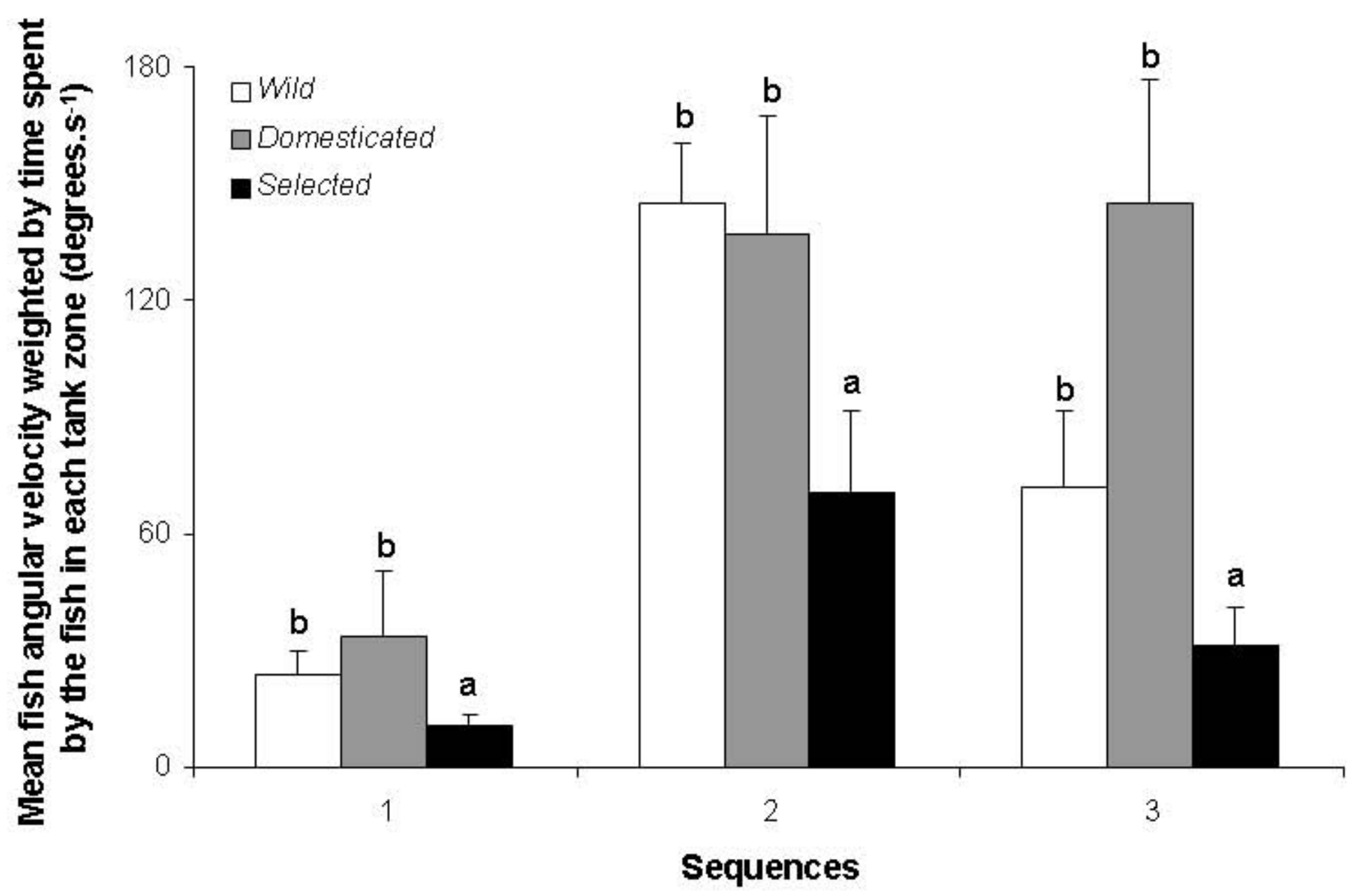

